SAN096-1629C

CONF-960628--1

\title{
NMR SPECTROSCOPIC INVESTIGATIONS OF SURFACE AND INTERLAYER SPECIES ON MINERALS, CLAYS AND OTHER OXIDES
}

\author{
R. James Kirkpatrick' \\ Yeongkyoo Kim ${ }^{1}$ \\ Charles A. Weiss ${ }^{2}$ \\ and \\ Randall T. Cygan ${ }^{3}$ \\ 'Department of Geology \\ University of Illinois \\ Urbana, IL 61801, USA \\ ${ }^{2}$ U. S. Army Engineer Waterways Experiment Station \\ Structures Laboratory \\ Vicksburg, MS 39180, USA \\ ${ }^{3}$ Geochemistry Department \\ Sandia National Laboratories \\ Albuquerque, NM 87185, USA
}




\section{DISCLAIMER}

This report was prepared as an account of work sponsored by an agency of the United States Government. Neither the United States Government nor any agency thereof, nor any of their employees, makes any warranty, express or implied, or assumes any legal liability or responsibility for the accuracy, completeness, or usefulness of any information, apparatus, product, or process disclosed, or represents that its use would not infringe privately owned rights. Reference herein to any specific commercial product, process, or service by trade name, trademark, manufacturer, or otherwise does not necessarily constitute or imply its endorsement, recommendation, or favoring by the United States Government or any agency thereof. The -views and opinions of authors expressed herein do not necessarily state or reflect those of the United States Government or any agency thereof. 


\section{INTRODUCTION}

The behavior of chemical species adsorbed on solid surfaces and exchanged into clay interlayers plays a significant role in controlling many natural and technologically important processes, including rheological behavior, catalysis, plant growth, transport in natural pore fluids and those near anthropogenic hazardous waste sites, and watermineral interaction. Adsorption and exchange reactions have been the focus of intense study for many decades (see, e.g., Stucki and Banwart, 1980; Sposito, 1984, 1989; Stumm, 1987; Hochella and White, 1990; and Güven and Pollastro, 1992, for introductions). Only more recently, however, have there been extensive spectroscopic studies of surface species (e.g., Fripiat, 1980; Brown and Parks, 1989; O'Day et al., 1994; Parfitt, 1979; Tejedor-Tejedor and Anderson, 1990). Among the spectroscopic methods useful for studying surface and exchanged species (e.g., infrared, X-ray photoelectron spectroscopy [XPS] and X-ray absorption spectroscopy [XAS]), nuclear magnetic resonance spectroscopy (NMR) has the considerable advantage of providing not only structural information via the chemical shift and quadrupole coupling constant but dynamical information in the $\mathrm{Hz}-\mathrm{mHz}$ range via lineshape analysis and relaxation rate measurements (see, e.g., Fripiat, 1980; Engelhardt and Michel, 1987; Kirkpatrick, 1988; Stebbins, 1988). It is also possible to obtain data in the presence of a separate fluid phase, which is essential for many applications. This paper illustrates the range of applications of NMR methods to surface and exchanged species through review of recent work from our laboratory on $\mathrm{Cs}$ in clay interlayers and $\mathrm{Cs}, \mathrm{Na}$ and phosphate adsorbed on oxide surfaces. The substrate materials used for these experiments and our long-term objectives are related to problems of geochemical interest, but the principals and techniques are of fundamental interest and applicable to a wide range of technological problems.

\section{INTERLAYER EXCHANGED Cs}

Cations exchanged into the interlayers of expandable clays (smectites; Brindley and Brown, 1980) are comparatively easy to study with NMR methods because the cations become major components of the phase and their concentrations are often several wt $\%$. In addition to $\mathrm{Cs}, \mathrm{Li}, \mathrm{Na}, \mathrm{K}$, and $\mathrm{Cd}$ have been studied by NMR (e.g., Bank et al., 1989; Luca et al., 1989; Laperche et al., 1990; Tinet et al., 1991; Kloprogge et al., 1992; Lambert et al., 1992). We have chosen to investigate ${ }^{133} \mathrm{CS}$ because it is a significant component of nuclear waste, because it provides an end-member case as the least electronegative cation, and because it has desirable nuclear properties $(100 \%$ abundance, relatively high frequency, $65.5 \mathrm{MHz}$ at $\mathrm{H}_{0}=11.7 \mathrm{~T}$, and small quadrupole moment).

Clays are ubiquitous in near surface geological environments and are used in a wide range of technological applications. Because many of them have large cation exchange capacities they greatly affect cation reactivity and transport in natural and hazardous waste environments, and they have found application as, e.g., sorbants and molecular sieves. The environments and dynamical behavior of interlayer cations have 
proven difficult to study directly, because most clays lack long-range order and, thus, the interlayer sites are poorly probed by diffraction methods. In contrast, NMR provides a direct probe of the local cation environments and their dynamical behavior.

The ${ }^{133} \mathrm{Cs}$ NMR behavior of Cs-exchanged smectites illustrates well the kinds of information that can be obtained. Smectites are phyllosilicates similar in some ways to micas. They have layer structures consisting of a sheet of octahedral sites sandwiched between two sheets of tetrahedral sites, the so called TOT or 2:1 structure. In most smectites the tetrahedral sites are occupied by $\mathrm{Si}$ and the octahedral sites by $\mathrm{Al}, \mathrm{Fe}$, $\mathrm{Mg}, \mathrm{Li}$ and other cations. The TOT layers develop net negative charge by allovalent substitution in both the octahedral and tetrahedral sites, causing the attraction of cations and water molecules into the interlayer regions. Cation exchange can be quite rapid, because the interlayer regions are two dimensional and exposed to exterior fluids.

We have done our experiments with hectorite, which is a 2:1 smectite that develops negative layer charge by substitution of $\mathrm{Li}$ for $\mathrm{Mg}$ in the octahedral sheet (Weiss et al., $1990 \mathrm{a}, \mathrm{b})$. Samples were prepared by multiple exchange in 1.0 and $0.1 \mathrm{M}$ solutions until essentially complete Cs-exchange was reached ( $97 \%$ of the interlayer cations). Temperature dependent data are essential to interpret the results, because there is rapid exchange of Cs among different interlayer sites at room temperature (RT).

At temperatures greater than $-10^{\circ} \mathrm{C}$, the ${ }^{133} \mathrm{CS}$ NMR spectrum of a Cs-exchanged hectorite in contact with $1.0 \mathrm{M} \mathrm{CsCl}$ solution (a slurry sample) consists of two peaks, one between 3.5 and 10.9 ppm and the other between -15.2 and -8.3 ppm (Figure 1). These peaks are readily assigned to $\mathrm{Cs}$ in the $\mathrm{CsCl}$ solution (positive peak) and $\mathrm{Cs}$ in the clay interlayer (negative peak). With decreasing temperature the peak for the solution disappears between -30 and $-40^{\circ} \mathrm{C}$ as the solution freezes and $\mathrm{CsCl}$ precipitates (peak at $228.1 \mathrm{ppm}$ ). The peak for $\mathrm{Cs}$ in the interlayer begins to split into two peaks at about $-20^{\circ} \mathrm{C}$, which at temperatures less than $-70^{\circ} \mathrm{C}$ have values near 27 and $-29 \mathrm{ppm}$. Such peak splitting is classical behavior for dynamical averaging between two sites, and the spectra can be used to determine frequencies of exchange between these two sites via line shape analysis. The two peaks are resolved at low temperature, because $C s$ is either not exchanging between the two sites or is doing so at frequencies an order of magnitude or more less than the peak separation, which is in the $\mathrm{kHz}$ range. As $\mathrm{Cs}$ atoms begin to exchange between the two sites with increasing temperature their nuclei take on a chemical shift that is the abundance weighted average for the two sites. Complete averaging occurs when the exchange frequency is approximately an order of magnitude greater than the peak splitting (ca. $10 \mathrm{kHz}$ here). For our samples averaging appears to begin near $-70^{\circ} \mathrm{C}$ and to be complete for most $\mathrm{Cs}$ near $-20^{\circ} \mathrm{C}$. There is some site heterogeneity, as can be expected for a complex natural sample.

The two interlayer sites at low temperatures are assigned to Cs tightly bonded to the oxygens of the basal surface (near -29 ppm) and to Cs less tightly bonded to the basal oxygens and located more in the center of the interlayer (near $27 \mathrm{ppm}$ ). For both of 
these types of sites, the $\mathrm{Cs}$ is also coordinated by water molecules. The water keeps the TOT layers separated and is also undergoing site exchange. Thus, space is available for the Cs to move among sites. The frequency of this motion, however, is orders of magnitude less than typical lattice vibrational frequencies and is probably best thought of as self-diffusion coupled to the motion of the water molecules.

The dynamical behavior of the slurry sample contrasts dramatically with the rigid Cs observed for a fully dehydrated Cs-exchanged hectorite (Figure 2). In the absence of interlayer water, $C s$ is present in two sites coordinated only by basal oxygens. These are probably 9 -coordinate (near $30 \mathrm{ppm}$ ) and 12-coordinate (near $-120 \mathrm{ppm}$ ). The other peaks in the spectra are spinning sidebands, which are the result of magic angle spinning and a relatively large site asymmetry unaveraged by atomic motion.

The results for the hectorite slurry sample also contrast with those for a Cs-exchanged vermiculite. Vermiculite is a 2:1 clay mineral that develops its layer charge primarily by Al for Si substitution in the tetrahedral sheet. The total substitution is also much greater than in smectites. Thus, the amount of negative charge and the distance to the interlayer cation from the site of charge development is much less in vermiculites than in hectorite. The net effects for vermiculite are that interlayer Cs causes the interlayer region to dehydrate and collapse, forcing Cs to occur in only one site (near $57 \mathrm{ppm}$, data not shown) and preventing any dynamical behavior near room temperature.

\section{Cs ADSORPTION ON SURFACES}

Cations adsorb on solid surfaces for the same fundamental reason that they exchange into clay interlayers or zeolitic cavities, that is, to balance local negative charge. The molecular scale mechanisms of surface adsorption, however, can be significantly different. In clay interlayers all the oxygen atoms of the basal surface are 2-coordinate by tetrahedral cations $(\mathrm{Si}, \mathrm{Al})$. Some exterior surfaces are structurally similar to clay interlayers, e.g., the basal surfaces of clay particles, but many surfaces are very different, containing large numbers of broken bonds and locally uncompensated charge. $\mathrm{pH}$ dependent hydrogen adsorption/desorption greatly affects surface charge, with positive charge occurring at low $\mathrm{pH}$ and negative charge at high $\mathrm{pH}$. The details vary greatly with bulk phase composition. For large, low-charge cations such as $\mathrm{Cs}$, the presence or absence of a bulk aqueous phase and relative humidity $(\mathrm{RH})$ have important effects. At low RH there are few water molecules on the surface, and the cations must interact directly with the surface oxygens. As RH increases the equilibrium number of surface water molecules increases, and at RH's approaching $100 \%$ there is a surface film many molecules thick that behaves like bulk water. For typical phyllosilicates (kaolinite and mica) there are 1,2, and 3 statistical monolayers of adsorbed water at $10 \%, 60 \%$ and $80 \%$ RH respectively (see, e.g. Newmann, 1987; Parks, 1990).

The ${ }^{133}$ CS NMR results for Cs on the surfaces of illite, kaolinite, boehmite and silica gel (Figure 3) show that for this large, low charge cation the surface behavior is quite 
similar to the interlayer behavior. They also illustrate the capabilities of NMR methods to probe surface species and the effects of RH on the structural environments and dynamical behavior of the Cs (Kim et al., 1996 and submitted). The samples were prepared by immersing $0.5 \mathrm{gm}$ of powdered solid in $50 \mathrm{ml}$ of $0.1 \mathrm{M} \mathrm{CsCl}$ solution at $25^{\circ} \mathrm{C}$ for 5 days. Final pH's were between 4.60 and 7.77, greater than the zero point of charge, except for boehmite, which has a ZPC of ca. 8.0 (Parks, 1965). The solution was removed from the samples by filtering through a millipore filter with no washing except when indicated. The extent of removal of the solution varies among the samples due to varying permeability and significantly affects the spectra. Silica gel is an amorphous, high surface hydrous silica. Illite is a 2:1 phyllosilicate with a composition approaching muscovite mica and little interlayer exchange capacity. Kaolinite is a 1:1 phyllosilicate with a sheet of tetrahedra occupied by Si linked to a sheet of octahedra occupied primarily by $\mathrm{Al}$. Boehmite is $\gamma-\mathrm{AlO}(\mathrm{OH})$ and has a layer structure based on $\mathrm{Al}-\mathrm{O}, \mathrm{OH}$ octahedra.

For boehmite (Figure 3D) the solution was removed very effectively by filtering, and only those Cs atoms tightly bound to the surface (Stern layer, see e.g., Güven and Pollastro, $1992)$ are preserved in the sample. The amount of adsorbed Cs is small (ca. 0.0016 atoms $/ \AA^{2}$ ), as expected at pH's less than the $\mathrm{ZPC}$. At ca. $0 \% \mathrm{RH}$ (over solid $\mathrm{P}_{2} \mathrm{O}_{5}$ ) there is one broad peak due to $\mathrm{Cs}$ in asymmetrical environments coordinated by surface oxygens and what few water molecules are on the surface. At higher RH's, the peaks are much narrower, indicative of $C s$ in very symmetrical, time-averaged environments coordinated to both surface oxygens and water molecules and probably undergoing exchange among sites at frequencies $>\mathrm{ca} .10 \mathrm{kHz}$. The chemical shifts become less positive as the surface $\mathrm{Ca} / \mathrm{H}_{2} \mathrm{O}$ ratio decreases, paralleling the variation in bulk solutions (Halliday et al., 1969).

For the silica gel (Figure 3A), the solution was removed slightly less effectively, and more Cs was left (ca. 0.0020 atoms $/ \AA^{2}$ ). The spectral behavior is quite similar to that of boehmite, except that there is a peak due to surface Cs coordinated by only water molecules and not in contact with the surface oxygens (so-called outer sphere complexes, see Sposito 1984,1989 ) at $30 \% \mathrm{RH}$. Complete dynamical averaging among sites at frequencies greater than ca. $10 \mathrm{kHz}$ occurs at $70 \% \mathrm{RH}$ and greater.

For illite (Figure 3B) the total amount of $\mathrm{Cs}$ adsorbed is two orders of magnitude larger (ca. 0.26 atoms $/ \AA^{2}$ ) due primarily to the permanent charge developed by substitution of Al for $\mathrm{Si}$ in the tetrahedral sites and to less efficient filtering of the solution caused by lower sample permeability. The maximum amount of hydrated $\mathrm{Cs}$ that can be accommodated on the illite surface is ca. 0.023 atoms $/ \AA^{2}$, close to the amount expected if the narrow, most negative peak and its small shoulder are due to $\mathrm{Cs}$ in direct contact with the surface oxygens (inner sphere complexes; see Sposito, 1984, 1989). The remainder of the $\mathrm{Cs}$ is in outer sphere complexes and gives rise to the larger more positive peaks. The illite crystallites are blocky, allowing both inner sphere and outer sphere Cs to adsorb on the crystallite tops and bottoms and on the broken edges of the sheets at the crystallite edges. At $30 \% \mathrm{RH}$, the inner sphere complexes resonate at $-8.5 \mathrm{ppm}$ (crystallite tops and bottoms) and near $0 \mathrm{ppm}$ (crystallite edges), whereas the 
outer sphere complexes resonate at ca. $80 \mathrm{ppm}$ (broad peak, tops and bottoms) and near $30 \mathrm{ppm}$ (broad peak, edges). Assignment of these peaks is based on the dependence of the chemical shifts on solid composition, solution composition, behavior on washing with DI water, and comparison with the results for smectites. As for the other samples, dynamical averaging at frequencies $>c a .10 \mathrm{kHz}$ occurs at higher RH's.

For kaolinite the sample permeability was very low and the solution was poorly removed. The spectra (Figure $3 \mathrm{C}$ ) are consequently complex, containing peaks for inner and outer sphere complexes, $\mathrm{CsCl}$ precipitate from residual solution (near 200 $\mathrm{ppm}$ ) and a complex spinning sideband pattern. Spectral resolution is poorer, but at $70 \% \mathrm{RH}$ for instance, inner sphere complexes resonate near $16 \mathrm{ppm}$ and outer sphere complexes near $31 \mathrm{ppm}$. Dynamical averaging of the inner and outer sphere complexes occurs at $70 \% \mathrm{RH}$, and at $100 \% \mathrm{RH}$ even the $\mathrm{CsCl}$ precipitate is dissolved in the water film and averaged.

Assignment of the observed peaks just described parallels that of Weiss et al. $(1990 a, b)$ for Cs in smectite interlayers. Peaks that are more shielded (negative), narrower, vary less with sample condition, vary more with sample composition, and have larger sidebands are assigned to $C s$ in inner sphere complexes. Peaks that are broader, less shielded, and that vary more with sample condition are assigned to $C s$ in outer sphere complexes.

The spectral behavior with varying temperature, sample washing and varying solution concentration provides strong confirming evidence for the assignments and also additional dynamical information. Variable temperature data for illite at $100 \% \mathrm{RH}$ (Figure 4) show that dynamical averaging at frequencies $>\mathrm{ca} .1 \mathrm{kHz}$ ceases near $-20^{\circ} \mathrm{C}$. At lower temperatures more Cs is transferred to inner sphere complexes (the more negative peak) as few water molecules remain on the surface due to freezing. The peaks also become broad, indicating statically asymmetric sites.

For illite and kaolinite with decreasing solution concentration (Figure 5) there are two important changes. The relative intensity for inner sphere complexes increases, and the chemical shifts become substantially less positive or more negative due to the reduced Cs/water ratio, especially for the outer sphere complexes. Washing with DI water removes most of the $\mathrm{Cs}$ in outer sphere complexes and causes spectral changes parallel to those caused by decreasing solution concentration (data not shown).

\section{Na ADSORPTION ON SURFACES AND COMPETITION WITH Cs}

The surface behavior of $\mathrm{Na}$ is similar to that of $\mathrm{Cs}$, except that inner sphere complexes are not observed. Although $\mathrm{Na}$ has the same charge as $\mathrm{Cs}$, it has a smaller ionic radius and thus a larger hydration energy. Consequently, Na retains its shell of hydration waters. For illite (Figure 6), outer sphere complexes resonate between -7.7 and $-1.1 \mathrm{ppm}$ and $\mathrm{NaCl}$ precipitate from residual solution occurs at $7.1 \mathrm{ppm}$. The peak at $-25.5 \mathrm{ppm}$ and the shoulder near $-20 \mathrm{ppm}$ are due to unexchangeable $\mathrm{Na}$ bound in 
the illite, as shown by spectra for non-exchanged samples. With increasing RH at RT the relative amount of $\mathrm{Na}$ in the surface water film increases, and the amount of $\mathrm{NaCl}$ precipitate decreases, as expected for an increasing thickness of the water film. The peak for the surface $\mathrm{Na}$ also narrows, indicating increased dynamical averaging of sites. For mixed $\mathrm{Cs} / \mathrm{Na}$ solutions, the relative amount of $\mathrm{Cs}$ in inner sphere sites increases with decreasing $\mathrm{Cs} / \mathrm{Na}$ ratio, indicating that $\mathrm{Cs}$ competes for sites next to the surface (the Stern layer; see Güven and Pollastro, 1992) more effectively than $\mathrm{Na}$ (data not shown).

\section{${ }^{31} P$ NMR OF SURFACE ADSORBED PHOSPHATE COMPLEXES}

The structural environments and dynamical behavior of surface phosphate species contrasts strongly with those of $\mathrm{Cs}$ and $\mathrm{Na}$ described above. For Al-containing substrates, phosphate forms strongly bonded inner sphere complexes through P-O-Al linkages. Our work on the ${ }^{31} \mathrm{P}$ NMR behavior of kaolinite boehmite, and $\gamma$-alumina reacted at $25^{\circ} \mathrm{C}$ for $24 \mathrm{hrs}$ with $\mathrm{KH}_{2} \mathrm{PO}_{4}$ solutions with concentrations from $10^{-1}$ to $10^{-4} \mathrm{M}$ and pH's from 3 to 11 are consistent with this idea but also indicate that amorphous $\mathrm{K}-\mathrm{H}$-aluminophosphate precipitates form under all conditions examined (Kim and Kirkpatrick, submitted). The absence of dynamical averaging is clearly indicated by the spectrum of a moist $\gamma$-alumina sample (Figure 7). The narrow peak near $+2 \mathrm{ppm}$ is due to phosphate in the solution, that near $-5 \mathrm{ppm}$ to inner sphere complexes, and that near $-12 \mathrm{ppm}$ to amorphous precipitates. The chemical shifts of the inner sphere complexes become less negative with increasing $\mathrm{pH}$, consistent with progressive deprotonation with increasing $\mathrm{pH}$ and rapid $\mathrm{H}$-exchange among surface phosphate sites.

\section{ACKNOWLEDGMENTS}

We would like to acknowledge the support of the U.S. Nuclear Regulatory Commission and the U.S. Department of Energy under Contract No. DE-AC04-94AL85000 to Sandia National Laboratories. 


\section{REFERENCES}

Bank, S., Bank, J. F., and Elis, P. D., Solid-state ${ }^{113} \mathrm{Cd}$ nuclear magnetic resonance study of exchanged montmorillonites, J. Phys. Chem., 1989, 93:4847.

Brown, G. E., and Parks, G. A., 1989, Synchrotron-based X-ray absorption studies of cation environments in earth materials, Reviews of Geophysics, 27:519.

Engelhardt, G, and Michel, D., 1987, High-Resolution Solid-State NMR of Silicates and Zeolites, John Wiley and Sons, New York.

Fripiat, J.J., 1980, The application of NMR to the study of clay minerals, in: Advanced Chemical Methods for Soil and Clay Minerals Research, J. W. Stucki and W. L. Banwart, eds, D. Reidel, Dordrecht.

Güven, N., and Pollastro, R. M., eds, 1992, Clay-Water Interface and its Rheological Implications, Clay Minerals Society, Boulder, CO, USA.

Halliday, J. D., Richards, R. E., and Sharp, R. R., 1969, Chemical shifts in nuclear resonances of caesium ions in solution, Proc. Royal Soc. London. 313:45.

Hochella, M. F., and White, A. F., eds, 1990, Mineral-Water Interface Geochemistry, The Mineralogical Society of America, Washington, D. C.

Kim, Y., Cygan, R. T., and Kirkpatrick, R. J., 1996, ${ }^{133} \mathrm{Cs}$ NMR and XPS investigation of cesium adsorbed on clay minerals and related phases, Geochim. Cosmochim. Acta. 60:1041.

Kim, Y., and Kirkpatrick, R. J., ${ }^{31} \mathrm{P}$ NMR investigation of phosphate adsorbed on kaolinite, boehmite, and $\gamma-\mathrm{Al}_{2} \mathrm{O}_{3}$, Envt. Sci. Technol.

Kim. Y., Kirkpatrick, R. J., and Cygan, R. T., submitted, ${ }^{133} \mathrm{Cs}$ NMR study of Cs on the surfaces of kaolinite and illite, Geochim. Cosmochim Acta.

Kirkpatrick, R. J., 1988, MAS NMR spectroscopy of minerals and glasses, in F. C. Hawthorne, ed., Spectroscopic Methods in Mineralogy and Geology, The Mineralogical Society of America, Washington, D. C.

Kloprogge, J. T., Jansen, J. B. H., Schuiling, R. D., and Geus, J. W., 1992, The interlayer collapse during dehydration of synthetic $\mathrm{Na}_{0.7}$-beidellite: $\mathrm{a}^{23} \mathrm{Na}$ solidstate magic-angle spinning NMR study, Clays Clay Minerals. 25, 457.

Lambert, J-F., Prost, R., and Smith, M. E., 1992, ${ }^{39} \mathrm{~K}$ solid-state NMR studies of potassium tecto- and phyllosilicates: the in situ detection of hydratable $\mathrm{K}^{+}$in smectites, Clays and Clay Minerals. 40:253. 
Laperche, V., Lambert, J. F., Prost, R., and Fripiat, J. J., 1990, High-resolution solidstate NMR of exchangeable cations in the interlayer surface of a swelling mica: ${ }^{23} \mathrm{Na},{ }^{111} \mathrm{Cd}$, and ${ }^{133} \mathrm{Cs}$ vermiculites, J. Phys. Chem. 94:8821.

Luca, V., Cardile, C. M., and Meinhold, R. H., 1989, High-resolution multinuclear NMR study of cation migration in montmorillonite, Clay Mineral. 24:115.

Newmann, A. C. D., 1987, The interaction of water with clay mineral surfaces, in A. C. D. Newmann, ed., Chemistry of Clays and Clay Minerals, Mineralogical Society, London.

O'Day, P. A, Brown, G. E., and Parks, G. A., 1994, X-ray absorption spectroscopy of cobalt(II) multinuclear surface complexes and surface precipitates on kaolinite, J. Colloid. Interface Sci. 165:269.

Parfitt, R. L., 1979, The nature of the phosphate-goethite $(\alpha-\mathrm{FeOOH})$ complex formed with $\mathrm{Ca}\left(\mathrm{H}_{2} \mathrm{PO}_{4}\right)$ at different surface coverage, Soil Sci. Soc. Amer. J. 43:623.

Parks, G. A., 1965, The isoelectric points of solid oxides, solid hydroxides, and aqueous hydroxo complex systems, Chem. Rev. 65:177.

Parks, G. A., 1990, Surface energy and adsorption at mineral/water interfaces: an introduction, in M. F. Hochella and A. F. White, eds., Mineral-Water Interface Geochemistry, The Mineralogical Society of America, Washington, D. C.

Sposito, G., 1984, The Surface Chemistry of Soils, Oxford University Press, Oxford.

Sposito, G., 1989, The Chemistry of Soils, Oxford University Press, Oxford.

Stebbins, J. F., 1988, NMR spectroscopy and dynamic processes in mineralogy and geochemistry, in F. C. Hawthorne, ed., Spectroscopic Methods in Mineralogy and Geology, The Mineralogical Society of America, Washington, D. C.

Stucki, J. W., and Banwart, W. L., eds, 1980, Advanced Chemical Methods for Soil and Clay Minerals Research, D. Reidel, Dordrecht.

Stumm, W., 1987, Aquatic Surface Chemistry, John Wiley and Sons, New York

Tejedor-Tejedor, M. I., and Anderson, M. A., 1990, Protonation of phosphate on the surface of goethite as studied by CIR-FTIR and electrophoretic mobility, Langmuir. 6:602.

Tinet, D., Faugere, A. M., and Prost, R., $1991,{ }^{113}$ Cd NMR chemical shift tensor analysis of cadmium-exchanged clays and clay gels, J. Phys. Chem. 95:8804. 
Weiss, C.A., Kirkpatrick, R. J., and Altaner, S. P., 1990a, The structural environments of cations absorbed onto clays: ${ }^{133} \mathrm{Cs}$ variable-temperature MAS NMR spectroscopic behavior of hectorite, Geochim. Cosmochim. Acta. 54:1655.

Weiss, C. A., Kirkpatrick, R. J., and Altaner, S. P., 1990b, Variations in interlayer cation sites in clay minerals as studied by ${ }^{133}$ Cs MAS nuclear magnetic resonance spectroscopy, Am. Mineral. 75:970. 


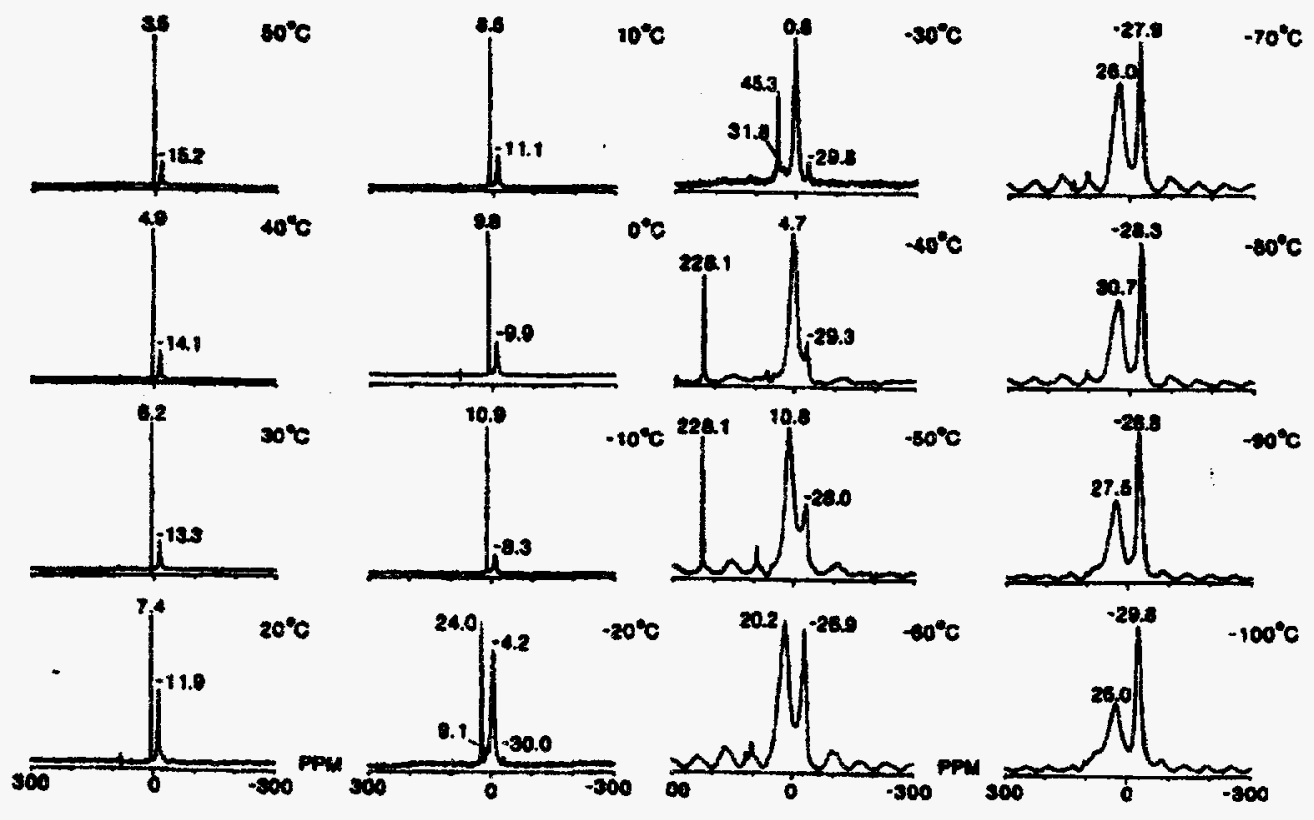

Figure 1. ${ }^{133} \mathrm{Cs}$ MAS NMR spectra of Cs-exchanged hectorite in a $1.0 \mathrm{M} \mathrm{CsCl} \mathrm{slurry} \mathrm{at}$ temperatures between 50 and $-100^{\circ} \mathrm{C}$. The $\mathrm{H}_{0}$ field strength was $8.45 \mathrm{~T}$. After Weiss et al., 1990a. 

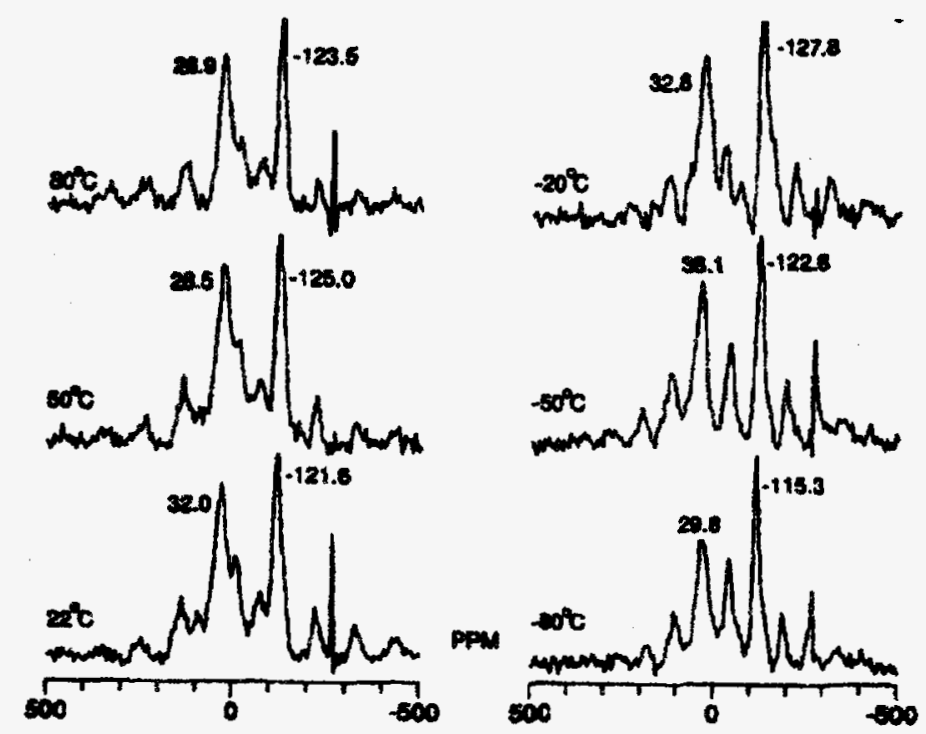

Figure 2. ${ }^{133} \mathrm{Cs}$ MAS NMR spectra of Cs-exchanged hectorite sample dehydrated at $500^{\circ} \mathrm{C}$ before analysis at temperatures from 80 to $-80^{\circ} \mathrm{C}$. The labeled peaks near -120 and $+30 \mathrm{ppm}$ are true center bands, and the other peaks are spinning sidebands. After Weiss et al., 1990a. 

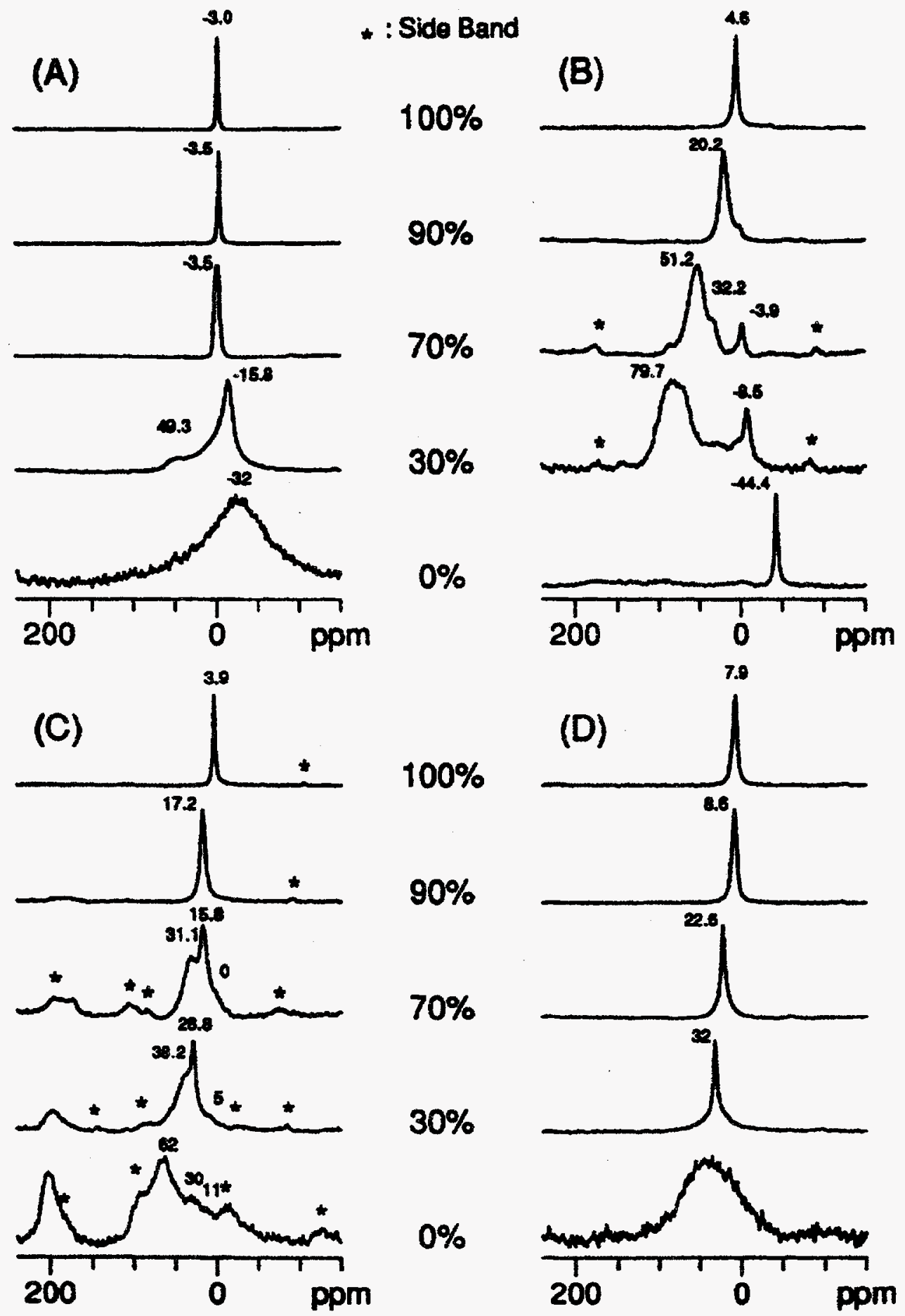

Figure 3. ${ }^{133} \mathrm{CS}$ MAS NMR spectra of Cs-exchanged (A) silica gel, (B) illite, (C) kaolinite, and (D) boehmite collected at $H_{0}=11.7 \mathrm{~T}$, room temperature and the indicated relative humidities. The peaks marked by * are spinning sidebands. After Kim et al., submitted. 


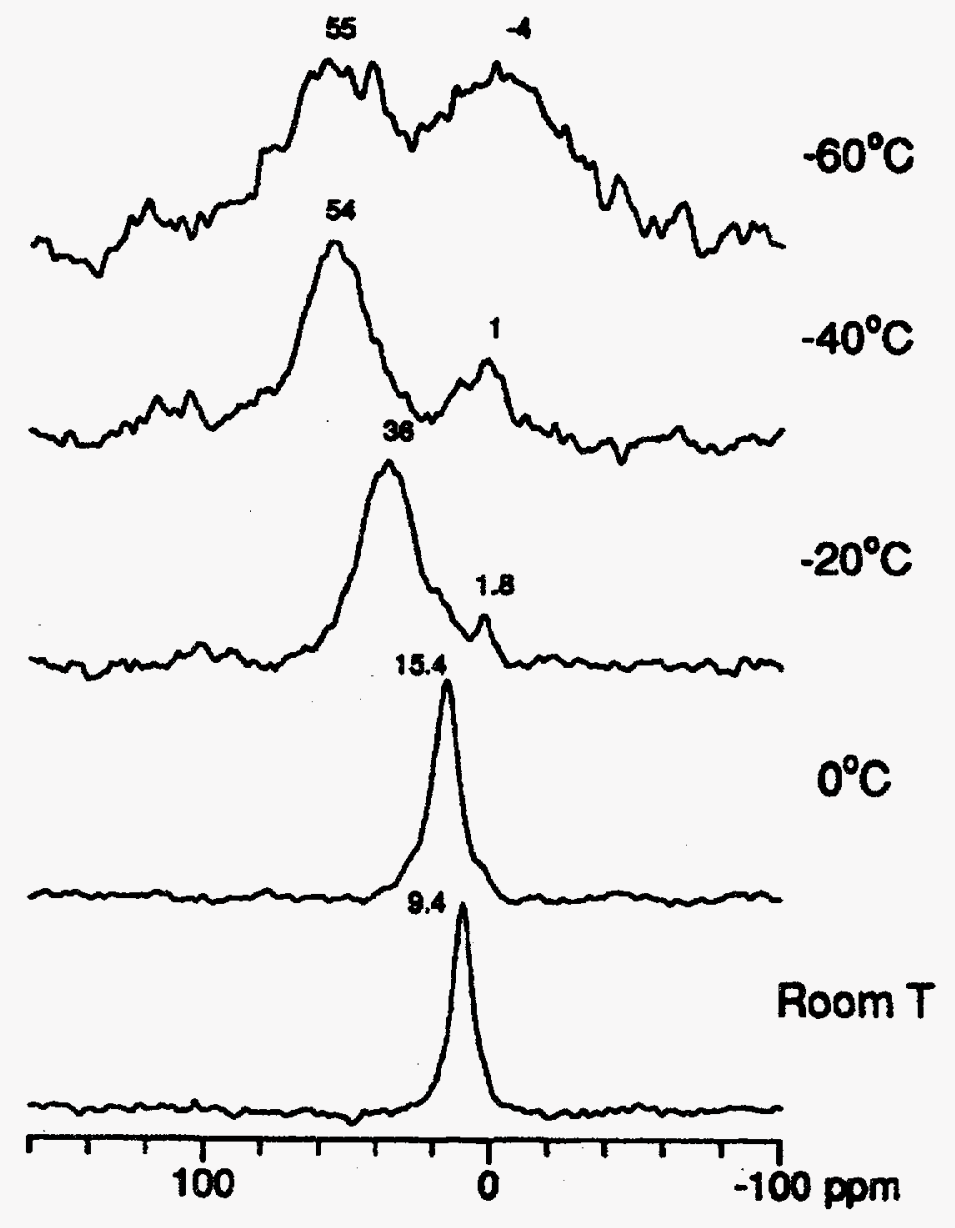

Figure 4. ${ }^{133} \mathrm{Cs}$ MAS NMR spectra of Cs-exchanged illite equilibrated at $100 \%$ relative humidity. $H_{\circ}=11.7 \mathrm{~T}$. Temperatures as labeled. After Kim et al., submitted. 
(A)
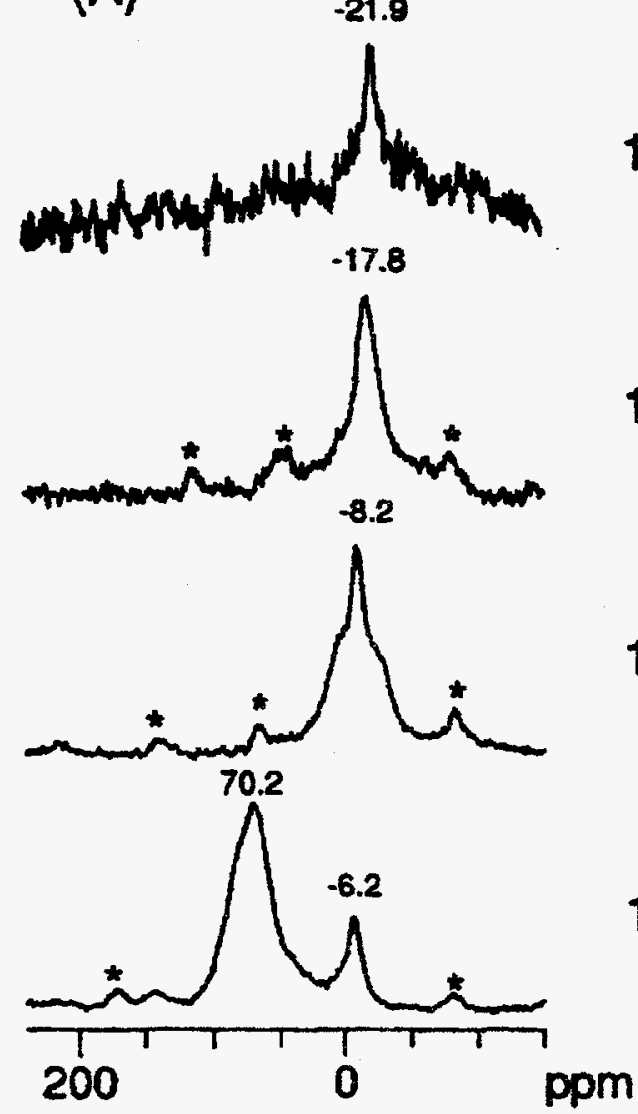

(B)
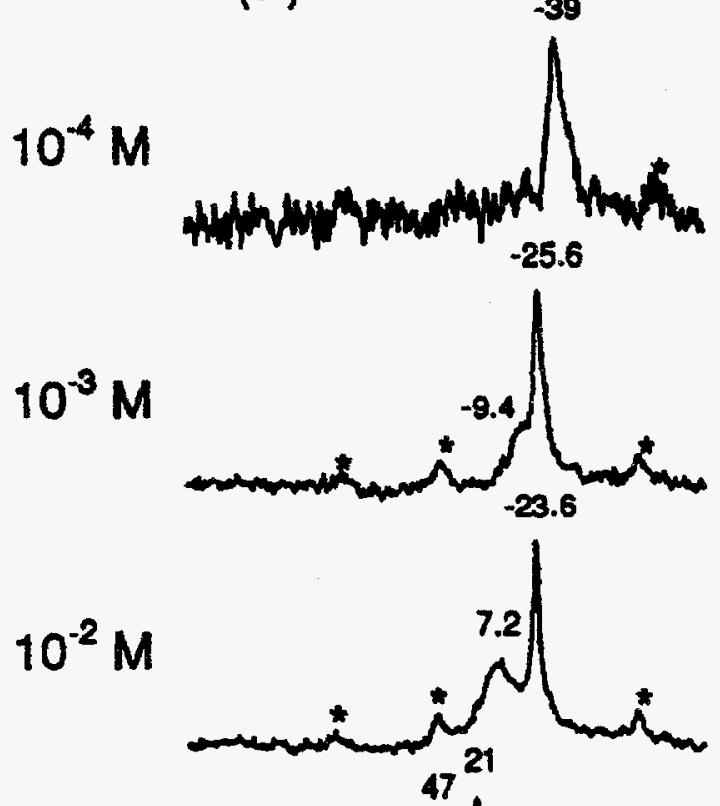

$10^{-1} \mathrm{M}$

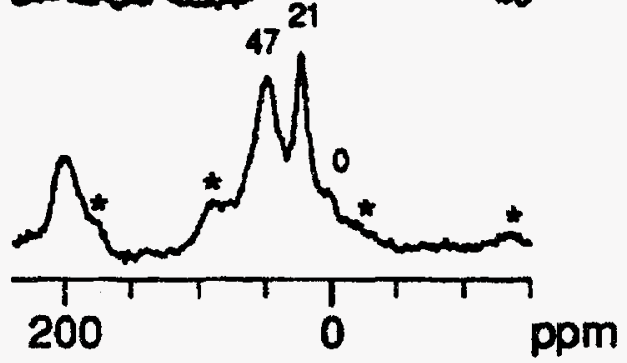

Figure 5. ${ }^{133} \mathrm{Cs}$ MAS NMR spectra of (A) illite and (B) kaolinite Cs-exchanged at the indicated $\mathrm{CsCl}$ solution concentrations and collected at room humidity (ca. $35 \% \mathrm{RH}$ ) and $H_{0}=11.7 \mathrm{~T}$. After Kim et al., submitted. 


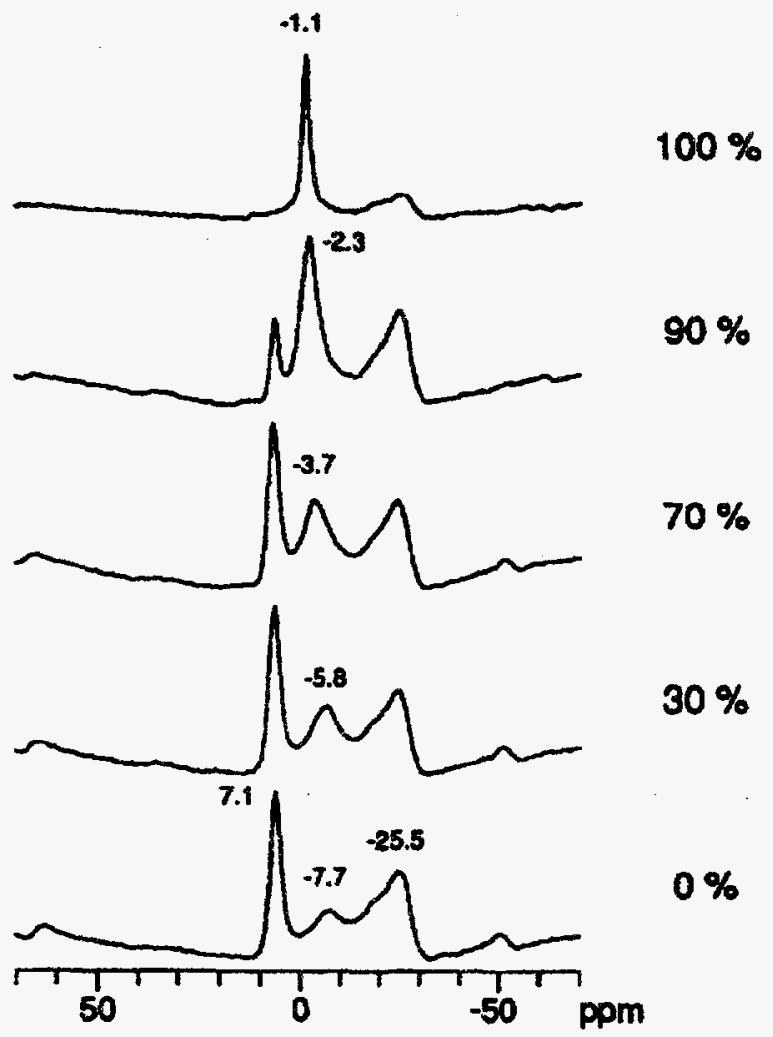

Figure 6. ${ }^{23} \mathrm{Na}$ MAS NMR spectra of illite exchanged in $0.1 \mathrm{M} \mathrm{NaCl}$ solutions at $25^{\circ} \mathrm{C}$. Spectra collected at $H_{0}=11.7 \mathrm{~T}$, room temperature, and room humidity (ca. $\left.35 \% \mathrm{RH}\right)$. 


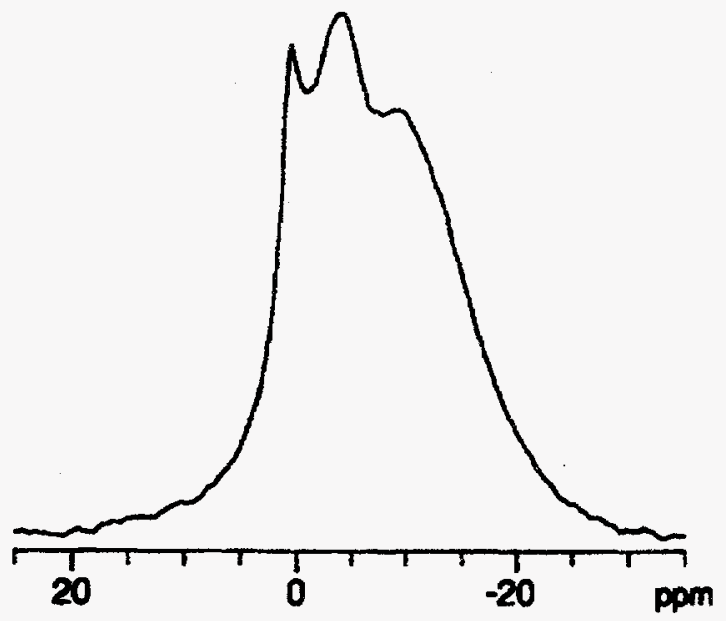

Figure 7. ${ }^{31} \mathrm{P}$ MAS NMR spectrum of a $\gamma$-alumina sample in a $0.1 \mathrm{M} \mathrm{KH}_{2} \mathrm{PO}_{4}$ solution at $\mathrm{pH} 5$. 